\title{
Sliding wear behaviors of Nomex fabric/phenolic composite under dry and water-bathed sliding conditions
}

\author{
Guina REN ${ }^{1,2}$, Zhaozhu ZHANG ${ }^{1, *}$, Xiaotao ZHU ${ }^{1}$, Xuehu MEN ${ }^{1, *}$, Wei JIANG ${ }^{1}$, Weimin LIU $^{1}$ \\ ${ }^{1}$ State Key Laboratory of Solid Lubrication, Lanzhou Institute of Chemical Physics, Chinese Academy of Sciences, Tianshui Road 18th, \\ Lanzhou 730000, PR China \\ ${ }^{2}$ University of Chinese Academy of Sciences, Beijing 100039, PR China \\ Received: 18 January 2014 / Revised: 03 March 2014 / Accepted: 20 March 2014 \\ (C) The author(s) 2014. This article is published with open access at Springerlink.com
}

\begin{abstract}
A Nomex fabric/phenolic composite was prepared, and its tribological properties were evaluated under dry and water-bathed sliding conditions by a pin-on-disk tribometer. The resulting size of the friction coefficient for the Nomex fabric/phenolic composite in the study occurred in the following order: dry sliding condition > distilled water-bathed sliding condition > sea water-bathed sliding condition. The fabric composite's wear rate from high to low was as follows: distilled water-bathed sliding condition $>$ sea water-bathed sliding condition > dry sliding condition. Under water-bathed sliding conditions, penetration of water into the cracks accelerated the composite's invalidation process, resulting in a higher wear rate. We also found that the extent of corrosion and transfer film formed on the counterpart pin significantly influenced the wear rate of the Nomex fabric composite. Discussion of the Nomex fabric composite's wear mechanisms under the sliding conditions investigated is provided on the basis of the characterization results.
\end{abstract}

Keywords: Nomex fabric/phenolic composite; friction and wear property; dry and water-bathed sliding condition

\section{Introduction}

Fabric-reinforced polymer composites display enhanced properties such as self-lubrication ability and excellent anti-wear compared with unreinforced polymer composites, metals, and alloys [1-3]. Therefore, fabricreinforced polymer composites have been employed as bearing liners in aircrafts and construction materials for automobiles and pressure vessels [4-6], all of which typically undergo friction and wear. In recent decades, researchers have comprehensively studied the tribological behaviors and mechanisms of fabric-reinforced polymer composites under dry sliding conditions [7-10]. However, studies related to their tribological properties under water-lubricated conditions are relatively rare, despite the fact that fabric-reinforced

* Corresponding author: Zhaozhu ZHANG, Xuehu MEN.

E-mail: zzzhang@licp.cas.cn (Zhaozhu ZHANG), xhmen@licp.cas.cn (Xuehu MEN) polymer composites will inevitably be used in rainy conditions, marine environment, and ultrahigh humidity environments whereby absorbed water molecules will affect their mechanical and tribological properties [11-14].

As a class of tribo-engineering materials, Nomex fabric-reinforced composites have various industrial applications. However, the friction and wear behavior of these composites under water-bathed sliding conditions have not yet been investigated with respect to their practical application. In this study, we systematically investigate the sliding wear behaviors of a Nomex fabric/phenolic composite under dry and water-bathed sliding conditions. We found the friction coefficient of the Nomex fabric composite under waterbathed sliding conditions to be much lower than that under dry a sliding condition. However, the wear rate for the Nomex fabric composite increased markedly under water-bathed sliding conditions compared with 
the rate measured under a dry sliding condition. In addition, we found that the Nomex fabric composite displayed different tribological behaviors when a distilled water-bathed sliding condition and sea waterbathed sliding condition were applied separately. These distinct tribological behaviors result from differences in the components of distilled water and sea water. This study provides a new avenue for basic research as well as real applications for fabric composites.

\section{Experimental}

\subsection{Materials}

Nomex fabric, knitted with the Nomex fibers from DuPont, has a plain weave with a weight/area ratio of $1.37 \mathrm{~g} / \mathrm{cm}^{2}$. Adhesive resin (204 phenolic resin) was provided by Shanghai Xing-guang Chemical Plant, China. The other chemicals of analytical grade were provided by Sinopharm Chemical Reagent Company and used as received.

Sea water was prepared according to ASTMD1141-98 standard [15], and its resultant composition is shown in Table 1.

\subsection{Specimen preparation}

The Nomex fabric was cleaned by a Soxhlet extractor in petroleum ether and ethanol in turn, and then dried in the oven. Next, the Nomex fabric was immersed in the adhesive diluted with the mixed solvent $V_{\text {acetone }}: V_{\text {ethanol }}: V_{\text {ethyl acetate }}=1: 1: 1$ and then dried. We performed a series of repetitive immersions and coatings of Nomex fabric until the mass fraction of

Table 1 Chemical composition of sea water (The chlorinity of the sea water is 19.38; the $\mathrm{pH}$ is 8.20 ).

\begin{tabular}{cc}
\hline Compound & Concentration $(\mathrm{g} / \mathrm{l})$ \\
\hline $\mathrm{NaCl}$ & 24.53 \\
$\mathrm{MgCl}_{2}$ & 5.20 \\
$\mathrm{Na}_{2} \mathrm{SO}_{4}$ & 4.09 \\
$\mathrm{CaCl}_{2}$ & 1.16 \\
$\mathrm{KCl}$ & 0.695 \\
$\mathrm{NaHCO}_{3}$ & 0.201 \\
$\mathrm{KBr}$ & 0.101 \\
$\mathrm{H}_{3} \mathrm{BO}_{3}$ & 0.027 \\
$\mathrm{SrCl}_{2}$ & 0.025 \\
$\mathrm{NaF}$ & 0.003 \\
\hline
\end{tabular}

fabric in the composite was about $70 \% \pm 5 \%$. Finally, the fabric composite was cut into pieces and affixed with the phenolic resin to an AISI-1045 steel disk $(\Phi 45 \mathrm{~mm} \times 8 \mathrm{~mm}$ in size, with a surface roughness of $0.45 \mu \mathrm{m}$ ) and then cured at $180{ }^{\circ} \mathrm{C}$ for $2 \mathrm{~h}$ under a specific pressure.

\subsection{Friction and wear tests}

A Xuanwu-III pin-on-disk tribometer (see Fig. 1) was used to study the tribological properties of two fabric composite samples. In this pin-on-disk tester, a stationary steel pin slides against the fabric composite specimen on a rotating steel disk with or without water. The flat-ended AISI-1045 pin (diameter $2 \mathrm{~mm}$ ) is secured to the load arm with a chuck. The distance between the center of the pin and the axis is $12.5 \mathrm{~mm}$. The pin has two degrees of freedom over the disk: vertical, for normal load applications by direct contact with the disk, and horizontal for friction measurement. A load cell sensor connected to the pin measured the frictional torque during the friction test. Before each wear test, the frictional torque was tuned to zero. When a wear test started, the pin was rotated to certain angles, and the frictional torque was obtained using computer software.

Before each test, the pin was polished successively with 350, 700, and 900 grade water-proof abrasive papers to a surface roughness ( $\mathrm{Ra}$ ) of $0.15 \mu \mathrm{m}$, and then cleaned with acetone. The sliding wear tests were performed at room temperature, at loads between $60 \mathrm{MPa}$ and $100 \mathrm{MPa}$, at a speed of $0.131 \mathrm{~m} / \mathrm{s}$, and over a $2 \mathrm{~h}$ period under dry and water-bathed sliding conditions. At the end of each test, the corresponding wear volume loss $(V)$ of the composite was obtained by measuring the depth of the wear scar with a

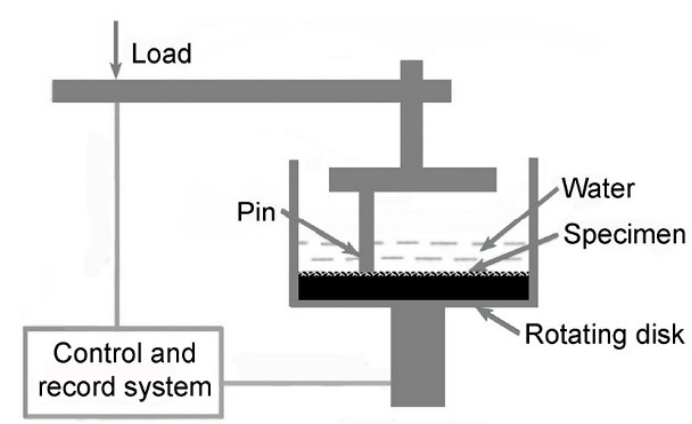

Fig. 1 Schematic diagram of pin-on-disc friction and wear tester. 
micrometer (resolution $0.001 \mathrm{~mm}$ ). The wear performance was expressed by the wear rate $\left(\omega, \mathrm{m}^{3}(\mathrm{~N} \cdot \mathrm{m})^{-1}\right)$ as follows: $\omega=V \cdot(P L)^{-1}$, where $V$ is the wear volume loss in $\mathrm{m}^{3}, P$ is the load in Newtons, and $L$ is the sliding distance in meters.

The friction coefficient, measured from the frictional torque in the load cell sensor, was obtained using a computer running friction-measure software. The contact temperature of the worn surface was monitored by a thermocouple positioned at the edge of the counterpart pin. Each experiment was carried out three times and the average value was used. The worn surfaces of the composites and the pins were analyzed using JSM-5600LV scanning electron microscopy (SEM). The chemical changes occurring on the counterpart pin under different conditions were analyzed on an ESCALAB 210 X-ray photoelectron spectroscope (XPS).

\section{Results and discussion}

\subsection{Tribological properties of Nomex fabric composite under different applied loads}

The wear and friction behaviors of the Nomex fabric composite were measured under a dry sliding condition and distilled water-bathed/sea water-bathed sliding conditions, respectively. Variations in the friction coefficient and wear rate of the Nomex fabric composite with applied load under dry and waterbathed sliding conditions is illustrated in Fig. 2. The friction coefficient and temperature of the worn surface of the Nomex fabric composite under an applied load

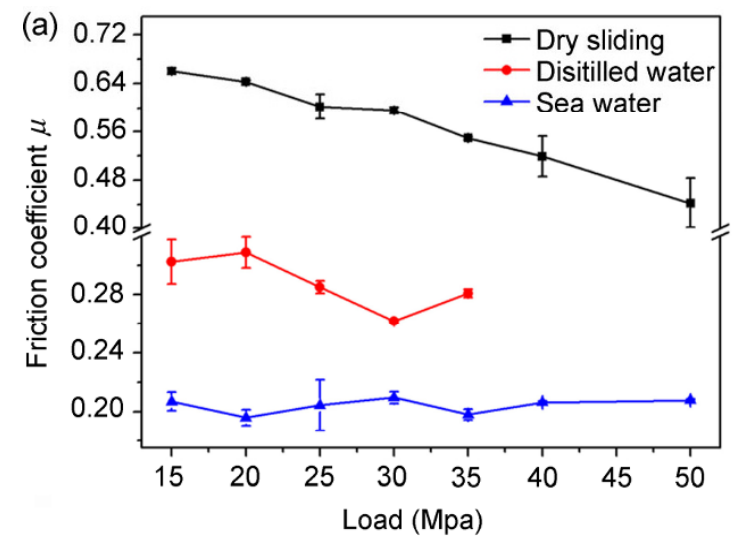

of $25 \mathrm{MPa}$ is plotted as a function of sliding time in Fig. 3. As shown in Figs. 2(a) and 3, under each applied load, the size of the friction coefficient and the worn surface temperature of the Nomex fabric composite occurs in the following order: dry sliding condition $>$ distilled water-bathed sliding condition $>$ sea water-bathed sliding condition. Under a load of $25 \mathrm{MPa}$, the friction coefficient of the Nomex fabric composite decreased from 0.602, measured under the dry sliding condition, to 0.285 , under the distilled water-bathed sliding condition, and then to 0.204, under the sea water-bathed sliding condition. We believe that the lubricating effect of the water film between the sliding pin and the fabric composite contributed to the decrease in the friction force and friction coefficient $[16,17]$.

Figure 2(b) shows the change in wear rate of the Nomex fabric composite with applied load under dry and water-bathed sliding conditions. Under all the applied loads investigated, the degree of wear rate of the Nomex fabric composite occurred in the following order: distilled water-bathed sliding condition $>$ sea water-bathed sliding condition $>$ dry sliding condition. When a load of $25 \mathrm{MPa}$ was applied, the wear rate of Nomex fabric composite clearly increased from $10.8 \times 10^{-14} \mathrm{~m}^{3}(\mathrm{~N} \cdot \mathrm{m})^{-1}$, measured under dry sliding condition, to $45.8 \times 10^{-14} \mathrm{~m}^{3}(\mathrm{~N} \cdot \mathrm{m})^{-1}$, under distilled waterbathed sliding condition, and to $23.9 \times 10^{-14} \mathrm{~m}^{3}(\mathrm{~N} \cdot \mathrm{m})^{-1}$, under sea water-bathed sliding condition. In addition, study results show that the load-carrying capacity of the Nomex fabric composite under a sea water-bathed sliding condition is better than that under a distilled

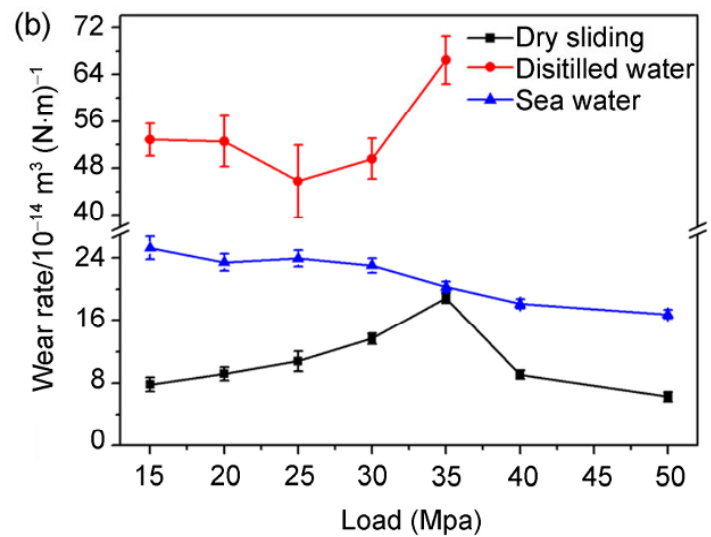

Fig. 2 The value of friction coefficient (a) and wear rate (b) of the fabric composite as a function of applied load. The sliding speed in the tests was $0.131 \mathrm{~m} / \mathrm{s}$. 

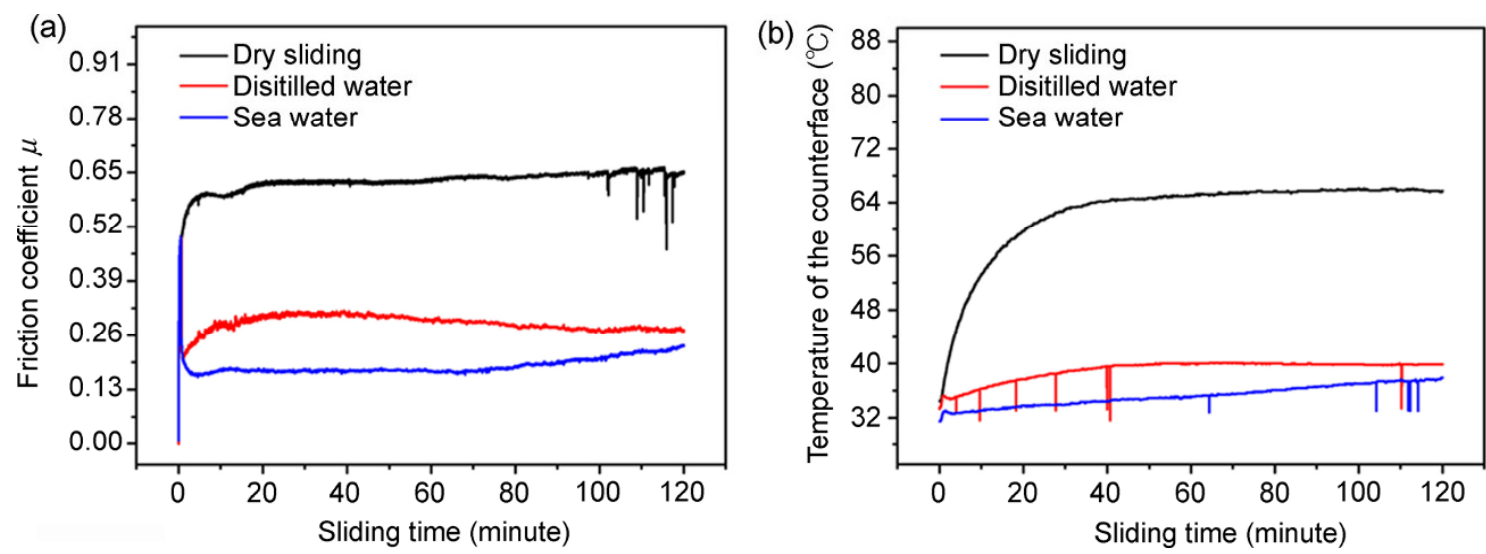

Fig. 3 The value of friction coefficient (a) and temperature of the counterface (b) of the fabric composite as a function of sliding time. The load and sliding speed in the tests were $25 \mathrm{MPa}$ and $0.364 \mathrm{~m} / \mathrm{s}$, respectively.

water-bathed sliding condition, though the capacity of both are worse than that under a dry sliding condition. For instance, the wear rate of the Nomex fabric composite under $35 \mathrm{MPa}$ was $18.9 \times 10^{-14} \mathrm{~m}^{3}(\mathrm{~N} \cdot \mathrm{m})^{-1}$, measured under a dry sliding condition, and $20.3 \times$ $10^{-14} \mathrm{~m}^{3}(\mathrm{~N} \cdot \mathrm{m})^{-1}$, measured under a sea water-bathed sliding condition. However, when the same load and sliding speed were applied, the Nomex fabric composite was worn out after sliding for 116 min under a distilled water-bathed sliding condition.

\subsection{SEM images of the worn surface of the Nomex fabric composite}

The absorption of water leads to damage of the interface in composites and a reduction in their mechanical and tribological properties. In a fabric composite, the penetration of water into the interface of its fiber and adhesive may cause them to debond. Accordingly, when the fabric composite is subjected to wear under distilled water-bathed/sea water-bathed sliding conditions, water inevitably penetrates into the micro cracks generated on the fabric composite's worn surface and the swelling effect also causes debonding of the fiber and adhesive [18, 19].

Figure 4 shows SEM images of the worn surfaces of the Nomex fabric composite tested under dry and water-bathed sliding conditions. The worn surface of a Nomex fabric composite tested under a dry sliding condition is smooth and flat (see Fig. 4(a)), and the magnified image suggests that no debonding or micro cracks existed on the worn surface. However, on the worn surface of the Nomex fabric composite tested under a distilled water-bathed sliding condition, the abrasion of the phenolic resin was severe. During the sliding process, water penetrated into the fabric composite along micro cracks, resulting in the waterswollen phenolic resin having lower shear strength $[18,19]$. Figures $4(\mathrm{~b})$ and $4(\mathrm{e})$ show that a large area of phenolic resin has detached from the composite, due to the damage caused by the shearing force and pressure. Comparatively, the worn surface of the Nomex fabric composite tested under a sea waterbathed sliding condition was only mildly damaged (see Figures 4(c) and 4(f)). Figure 6(c) shows that a large area of the worn surface was smooth without patches of resin debris attached. Figure 4(f) also shows that only some of the micro cracks are not spread out. These results suggest that the Nomex fabric/phenolic composite is more durable under a sea water-bathed sliding condition than under a distilled water-bathed sliding condition.

\subsection{Characterizations of the counterpart pin surface}

The surface composition and morphology of the counterpart pins sliding against the Nomex fabric composites were also analyzed. Table 2 shows the content of the element on the counterpart pin surface. By analyzing the composition of the three counterpart pins tested under different sliding conditions, we found that the counterpart pin in the distilled waterbathed sliding condition caused the most serious erosion, as evidenced by the large Fe2p content (see Table 1). In the XPS spectra of Fe2p in the counterpart pin under a distilled water-bathed sliding condition, 


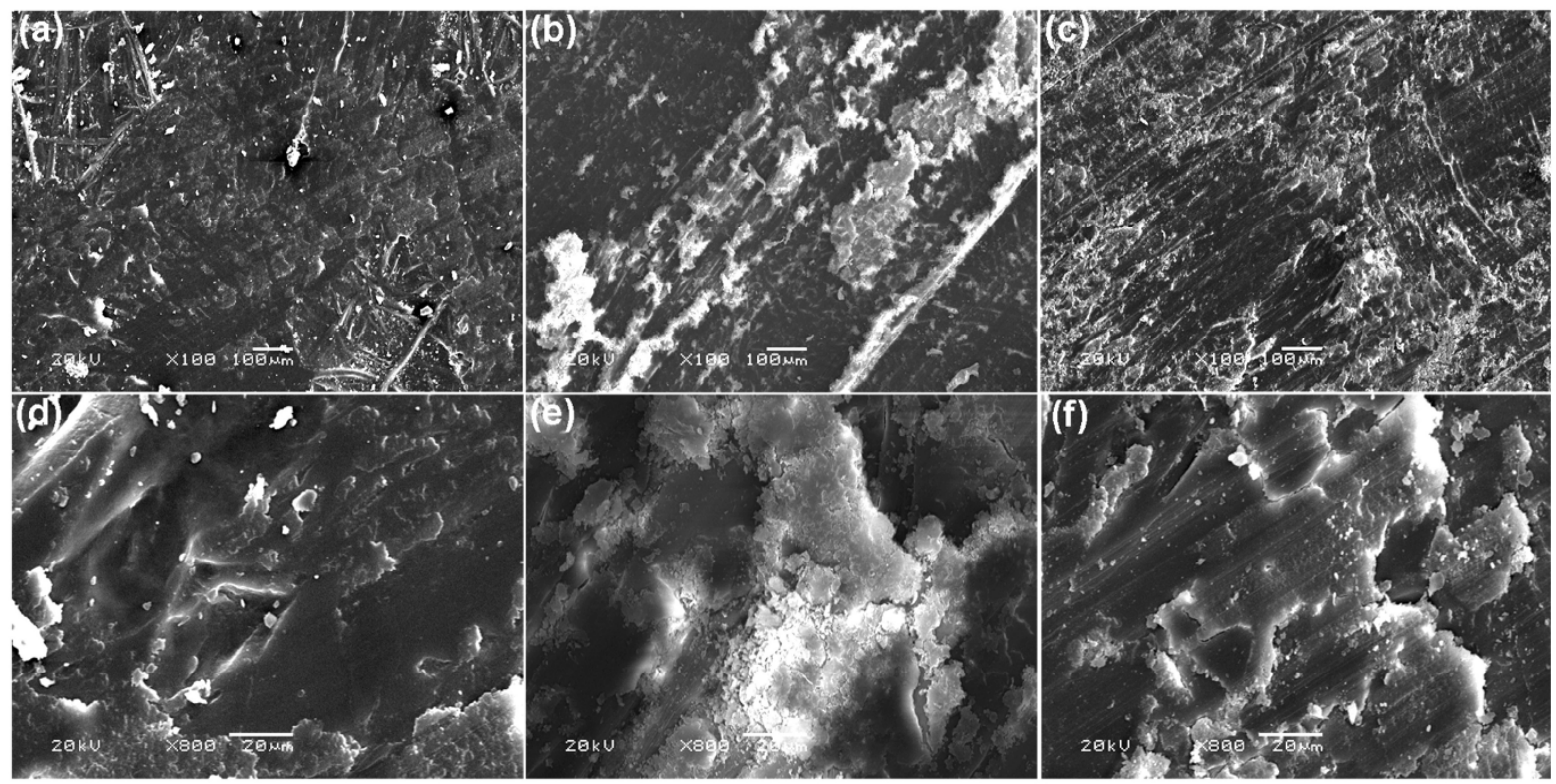

Fig. 4 SEM images of the worn surfaces for fabric composites tested under different sliding conditions: (a) Under dry sliding condition, (b) under distilled water-bathed sliding condition, and (c) under sea water-bathed sliding condition. (d), (e), and (f) are the magnified images of (a), (b), and (c), respectively. The applied load and sliding speed in the tests were $25 \mathrm{MPa}$ and $0.131 \mathrm{~m} / \mathrm{s}$, respectively.

Table 2 Relative atomic concentration of worn surfaces of the steel pin Nomex fabric composite slid against under different conditions.

\begin{tabular}{cccccccc}
\hline \multirow{2}{*}{$\begin{array}{c}\text { Wear } \\
\text { condition }\end{array}$} & \multicolumn{8}{c}{ Atomic percent } \\
\cline { 2 - 7 } & $\mathrm{C}$ & $\mathrm{N}$ & $\mathrm{O}$ & $\mathrm{Fe}$ & $\mathrm{Na}$ & $\mathrm{Mg}$ & $\mathrm{Ca}$ \\
\hline Ambient & 58.75 & 4.255 & 33.505 & 3.54 & & & \\
$\begin{array}{c}\text { Distilled } \\
\text { water }\end{array}$ & 59.105 & 0.11 & 30.595 & 10.18 & & & \\
Sea water & 52.185 & 4.42 & 26.845 & 2.85 & 0.825 & 10.64 & 2.235 \\
\hline
\end{tabular}

we attribute the peaks at $710.5 \mathrm{eV}$ and $724 \mathrm{eV}$ to $\mathrm{Fe}_{2} \mathrm{O}_{3}$ and the peak at $712.1 \mathrm{eV}$ to $\mathrm{FeSO}_{4}$ (see Fig. 5(a)). For the counterpart pin under the sea water-bathed sliding condition, we ascribe the peak at $712 \mathrm{eV}$ to $\mathrm{FeSO}_{4}$ (see Fig. 5(b)) [20]. That is, the oxidation of Fe was restrained under the sea water-bathed sliding condition, which may have contributed to the lower wear rate of the fabric composite under the sea water-bathed sliding condition than in the distilled water-bathed sliding condition. The XPS analysis of the counterpart pin under a sea water-bathed sliding condition indicates the presence of $\mathrm{NaCl}, \mathrm{CaCO}_{3}$, and $\mathrm{Mg}(\mathrm{OH})_{2}$ deposits on the pin surface. As shown in Figs. 5(c), 5(d), and 5(e), the peaks at 1,072 eV, $49.94 \mathrm{eV}$, and $351 \mathrm{eV}$ can be ascribed to $\mathrm{NaCl}, \mathrm{Mg}(\mathrm{OH})_{2}$, and $\mathrm{CaCO}_{3}$ deposits, respectively. The chemical reactions for the formation of $\mathrm{NaCl}, \mathrm{CaCO}_{3}$, and $\mathrm{Mg}(\mathrm{OH})_{2}$ in the white film during wear testing are as follows: [21]

$$
\begin{gathered}
\mathrm{Mg}^{2+}+2 \mathrm{H}_{2} \mathrm{O} \rightarrow \mathrm{Mg}(\mathrm{OH})_{2}+2 \mathrm{H}^{+} \\
\mathrm{HCO}^{3-} \rightarrow \mathrm{CO}_{3}{ }^{2-}+\mathrm{H}^{+} \\
\mathrm{Ca}^{2+}+\mathrm{CO}_{3}{ }^{2-} \rightarrow \mathrm{CaCO}_{3}
\end{gathered}
$$

After the sliding of the counterpart pin against the Nomex fabric composite under an ambient sliding condition scratches were detected and the transfer film was compact though discontinuous (Fig. 6(a)). When tested under a distilled water-bathed sliding condition, a rather thin and discontinuous transfer film can be seen on the counterpart pin, which has a high level of roughness and to which wear debris is attached. Eroded spots caused by the erosion of $\mathrm{Fe}$ were also detected (see Fig. 6(b)). We deduced that the cooling effect of water hindered the melting of the phenolic resin and inhibited the transfer and generation of wear debris on the sliding counterpart pin [22]. Under the sea water-bathed sliding condition, the surface of the counterpart pin after testing was much smoother and had no continuous covering of transfer film. However, a discontinuous white film was detected on the surface of the pin. We made the assumption that the white film was mainly composed of deposits of $\mathrm{NaCl}, \mathrm{CaCO}_{3}$, and $\mathrm{Mg}(\mathrm{OH})_{2}$. As seen 

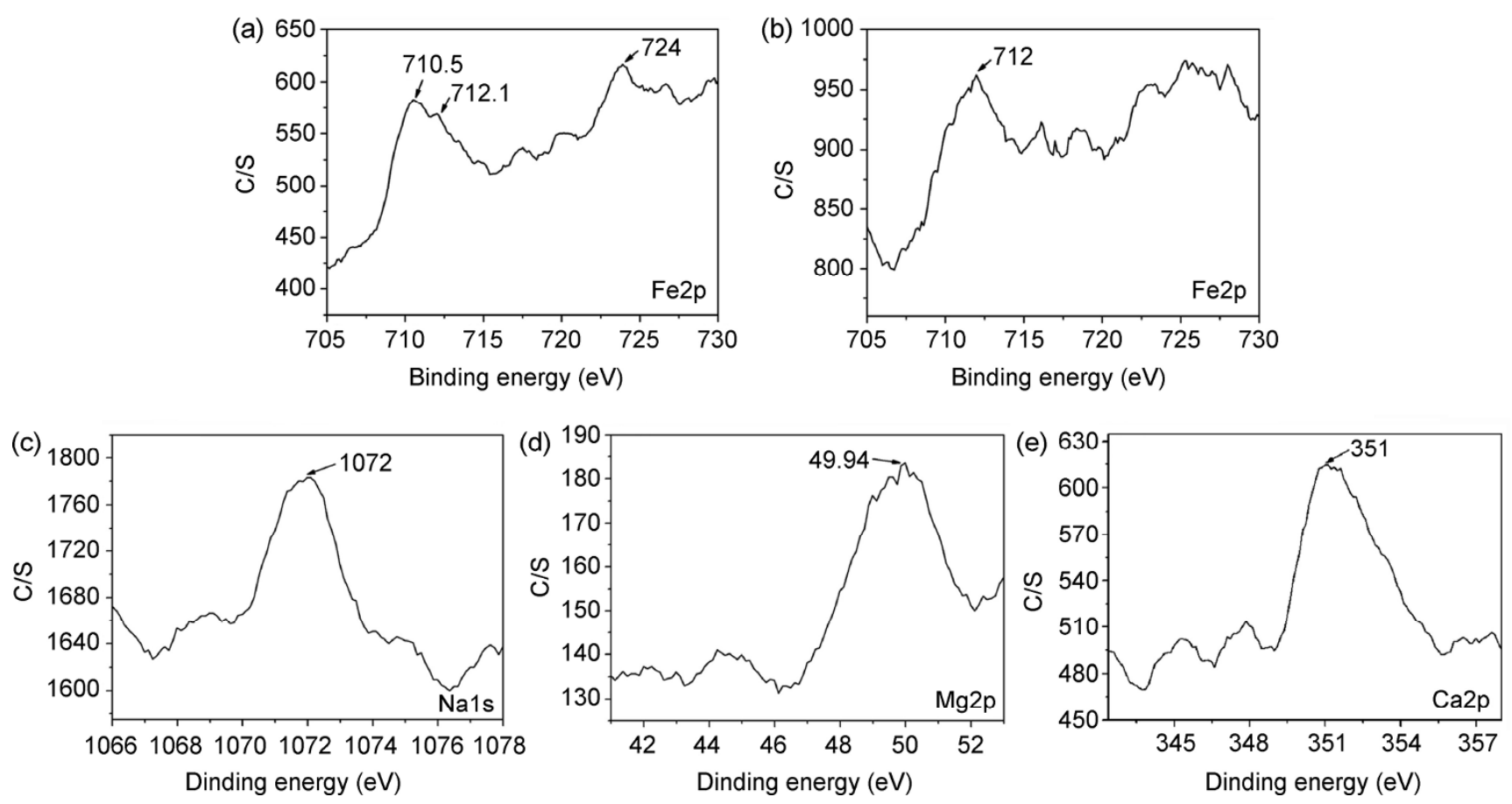

Fig. 5 XPS analysis of the counterpart pins sliding against fabric composites under different sliding conditions. Fe $2 p$ XPS spectrum of the pin surface sliding against fabric composites under distilled water-bathed sliding condition (a); Fe 2p (b), Na 1s (c), Mg 2p (d), Ca $2 p$ (e) XPS spectrum of the pin surface sliding against fabric composite under sea water-bathed sliding condition. The applied load and sliding speed in the tests were $25 \mathrm{MPa}$ and $0.131 \mathrm{~m} / \mathrm{s}$, respectively.
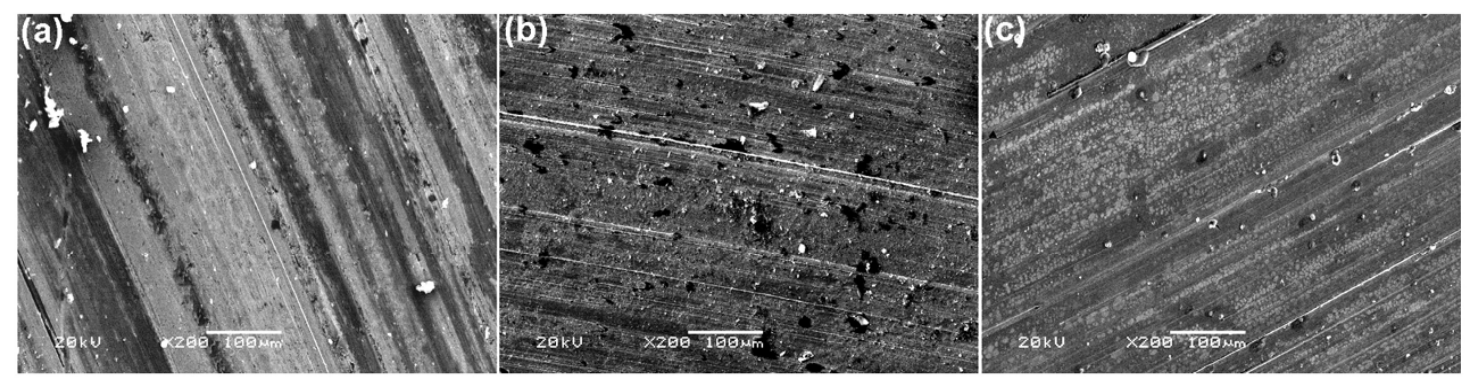

Fig. 6 SEM images of the counterpart pins sliding against fabric composites under different sliding conditions: (a) Under dry sliding condition, (b) under distilled water-bathed sliding condition, and (c) under sea water-bathed sliding condition. The applied load and sliding speed in the tests is $25 \mathrm{MPa}$ and $0.131 \mathrm{~m} / \mathrm{s}$, respectively.

in Fig. 6(c), the $\mathrm{NaCl}, \mathrm{CaCO}_{3}$, and $\mathrm{Mg}(\mathrm{OH})_{2}$ deposits were mainly along the grooves. We thus deduced that the grooves contributed to the deposition of $\mathrm{NaCl}$, $\mathrm{CaCO}_{3}$, and $\mathrm{Mg}(\mathrm{OH})_{2}$ and these $\mathrm{NaCl}, \mathrm{CaCO}_{3}$, and $\mathrm{Mg}(\mathrm{OH})_{2}$ deposits reduced the roughness of the pin surface. In addition, this film had a high resistance which could serve to isolate the steel surface from the corrosive medium, preventing $\mathrm{Cl}^{-}$and $\mathrm{O}_{2}$ from diffusing onto the surface of the steel, and thus reducing corrosion of the steel. Wang [21] et al. pointed out that a medium affects a polymer's tribological behavior mainly through corrosion to the counterface and the wear rate of a polymer depends on the extent of corrosion to the counterface. Accordingly, the Nomex fabric composite exhibits a higher wear rate under a distilled water-bathed sliding condition than under a sea water-bathed sliding condition.

\section{Conclusions}

In this study, we investigated the tribological behaviors of a Nomex fabric/phenolic composite under dry and 
water-bathed sliding conditions. We proposed that the penetration of distilled water/sea water induces damage to the mechanical properties of the Nomex fabric composite. Wear test results show that the wear resistance of the Nomex fabric/phenolic composite was much higher under a sea water-bathed sliding condition than under a distilled water-bathed sliding condition, owing to the $\mathrm{NaCl}, \mathrm{Mg}(\mathrm{OH})_{2}$, and $\mathrm{CaCO}_{3}$ deposited on the pin surface. We conclude that the transfer film formed on the counterpart pin and extent of erosion to the pin were the two main factors determining the friction and wear properties of the fabric composites.

\section{Acknowledgements}

The authors acknowledge the financial support of the National Science Foundation of China grant Nos. 51375472 and 51305429.

Open Access: This article is distributed under the terms of the Creative Commons Attribution License which permits any use, distribution, and reproduction in any medium, provided the original author(s) and source are credited.

\section{Refferences}

[1] Kumaresan K, Chandramohan G, Senthilkumar M, Suresha B, Indran S. Dry sliding wear behaviour of carbon fabricreinforced epoxy composite with and without silicon carbide. Compos Interface 18: 509-526 (2011)

[2] Huang T, Lu R G, Ma Y N, Liu P, Li T S. Study on the friction and sliding wear behavior of hybrid polytetrafluoroethylene/ Kevlar fabric composites filled with polyphenylene sulfide. J Macromol Sci B 51: 109-124 (2012)

[3] Qi X W, Jia Z N, Yang Y L. Influence of the dispersion of nano titanium dioxide on the tribological performance of fabric self-lubricating liner. J Appl Polym Sci 130(3): 21002105 (2013)

[4] Cao L, Shen X J, Li R Y. Three-dimensional thermal analysis of spherical plain bearings with self-lubricating fabric liner. Adv Mat Res 97-101: 3366-3370 (2010)

[5] Qiu M, Gao Z L, Yao S J, Chen L. Effects of oscillation frequency on the tribological properties of self-lubrication spherical plain bearings with PTFE woven liner. Key Eng Mater 455: 406-410 (2011)
[6] Cai Y Z, Yin X W, Fan S W, Zhang L T, Cheng L F. Tribological behavior of three-dimensional needled ceramic modified carbon/carbon composites in seawater conditions. Compos Sci Technol 87: 50-57 (2013)

[7] Piht1l1 H, Tosun N M. Effect of load and speed on the wear behaviour of woven glass fabrics and aramid fibre-reinforced composites. Wear 252: 979-984 (2002)

[8] Sharma M, Bijwe J. Surface designing of carbon fabric polymer composites with nano and micron sized PTFE particles. J Maters Sci 47: 4928-4935 (2012)

[9] Suresha B, Shiva Kumar K N. Investigations on mechanical and two-body abrasive wear behaviour of glass/carbon fabric reinforced vinyl ester composites. Mater Design 30: 20562060 (2009)

[10] Ren G N, Zhang Z Z, Zhu X T, Ge B, Guo F, Men X H, Liu W M. Influence of functional graphene as filler on the tribological behaviors of Nomex fabric/phenolic composite. Compos Part A: Appl Sci Manuf 49: 157-164 (2013)

[11] Zhang X R, Pei X Q, Wang Q H. Study on the friction and wear behavior of surface-modified carbon nanotube filled carbon fabric composites. Polym Adv Technol 22: 2157-2165 (2011)

[12] Wan Y Z, Huang Y, He F, Li Q Y, Lian J J. Tribological properties of three-dimensional braided carbon/Kevlar/epoxy hybrid composites under dry and lubricated conditions. Mater Sci Eng A 452-453: 202-209 (2007)

[13] Dhieb H, Buijnsters J G, Eddoumy F, Vázquez L, Celis J P. Surface and sub-surface degradation of unidirectional carbon fiber reinforced epoxy composites under dry and wet reciprocating sliding. Composites Part A: Appl Sci Manuf 55: 53-62 (2013)

[14] Lancaster J K. Lubrication of carbon fiber-reinforced polymers part I-water and aqueous solutions. Wear 20: 315-333 (1972)

[15] ASTM International. Standard practice for the preparation of substitute ocean water. ASTM D1141 (2003)

[16] Liu G Q, Wang X L, Zhou F, Liu W M. Tuning the tribological property with thermal sensitive microgels for aqueous lubrication. ACS Appl Mater Interfaces 5: 10842 10852 (2013)

[17] Ginzburg B M, Tochil'nikov D G, Lyashkov A I, Ugolkov V L, Lavrent'ev V K, Shijan P A, Ponimatkin V P. Tribological properties of poly(para-phenylene sulfide) and its carbon fiber composites with water lubrication. $J$ Macromol Sci B 50: 1047-1061 (2011)

[18] Wang Q H, Zhang X R, Pei X Q. Study on the synergistic effect of carbon fiber and graphite and nanoparticle on the friction and wear behavior of polyimide composites. Mater Design 31: 3761-3768 (2010) 
[19] Meng H, Sui G X, Xie G Y, Yang R. Friction and wear behavior of carbon nanotubes reinforced polyamide 6 composites under dry sliding and water lubricated condition. Compos Sci Technol 69: 606-611 (2009)

[20] Zhang H J, Zhang Z Z, Guo F, Jiang W, Wang K. Friction and wear of hybrid PTFE/Kevlar fabric composite filled with $\mathrm{ZnO}$ nanoparticles sliding against steel, copper, and aluminum. Tribol Trans 52: 833-840 (2009)

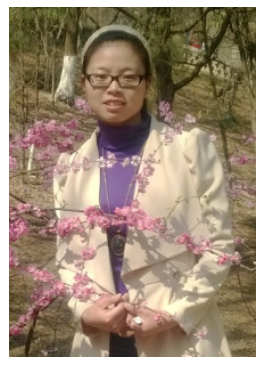

Guina REN. She is currently a $\mathrm{PhD}$ student at Lanzhou Institute of Chemical Physics, Chinese Academy Science. She received her Bachelor degree in Chemistry from Shandong Normal University in 2010. She

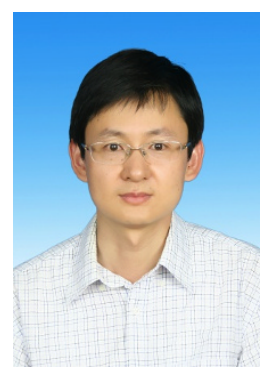

Xuehu MEN. He is currently an associate professor at Lanzhou Institute of Chemical Physics, Chinese Academy Science. He received his BS degree from Lanzhou University in 2001 and a PhD degree from Lanzhou Institute

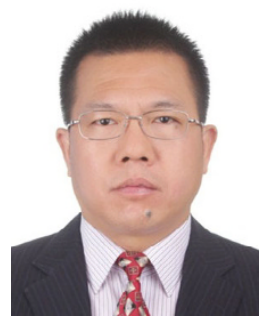

Zhaozhu ZHANG. He is currently a group leader at Lanzhou Institute of Chemical Physics, Chinese Academy Science. He received his PhD degree from Lanzhou Institute of Chemical Physics in 1998. His
[21] Wang J Z, Yan F Y, Xue Q J. Tribological behavior of PTFE sliding against steel in sea water. Wear 267: 1634 1641 (2009)

[22] Sumer M, Unal H, Mimaroglu A. Evaluation of tribological behaviour of PEEK and glass fibre reinforced PEEK composite under dry sliding and water lubricated conditions. Wear 265: 1061-1065 (2008)

joined Prof. Zhaozhu Zhang's group at Lanzhou Institute of Chemical Physics in 2010. Her current research interests are focused on improving the tribological properties of the fabric reinforced composites and studying the corresponding mechanism.

of Chemical Physics in 2009. His current research interests include the development of polymer composite materials and carbon based materials for lubrication and designing materials with special surface wettability. He is the author of more than 50 journal papers and several patent applications.

current research interests cover the tribology of composite materials, designing functional surfaces with special wetting behavior, and engineering coatings for drag-reduction. He has published over 150 journal papers and gained a number of national scientific awards. 